\title{
EFFECT OF LOW DOSE PROPRANONOL ON PERIOPERATIVE STRESS INDUCED HEMODYNAMIC CHANGES IN UPPER ABDOMINAL SURGERY
}

\author{
Dilip Kumar Saha', Md. Abdul Kader², Md Mostofa Kamal ${ }^{3}$, AKM Akhtaruzzaman ${ }^{3}, \mathrm{KM} \mathrm{Iqbal}^{4}$
}

\section{SUMMARY:}

Stress response is accompanied by an increased traffic in sympathetic efferent tracts resulting in potentially severe hypertension, tachycardia and is associated with post-operative morbidity. Study establishes the assumption that 'stress free' general anesthesia is necessarily advantageous. A recent study has suggested that different pre-medication may lead to an alteration in sympatho-adrenal stress response during surgery. Several agents and regimens have been devised to control this stress induced haemodynamic responses including alphablocker droperidol, lignocaine, low dose opioid and cervical extradural blockade.

It has been demonstrated that beta-adrenoceptor blocker, in therapeutic doses, caused only modest reduction in cardiac output while decreasing the incidence of arrhythmia and myocardial ischaemia after laryngoscopy and intubation. It is recommended that their administration to be continued until the day of surgery. Even a single dose of a beta-blocker given as a premedication decreases the incidence of episodes of myocardial ischaemia. Atenolol, a selective beta-blocker, per oral significantly reduces cardiovascular morbidity in non-cardiac surgery. Propranolol, a non-selective beta-blocker, has an added advantage of alleviating effect in anxiety. In addition, cost of propranolol is generally low and the systems required to use them according to the protocol used in this study are already in place.

This prospective study was performed to establish its effects on per-operative haemodynamic response in non-cardiac surgery.

The effect of propranolol on heart rate, systolic arterial pressure and derived value rate pressure product (RPP) on peri-operative period was significantly different from that of placebo effect. The result showed that propranolol significantly reduces heart rate, SAP \& thus $R P P$ \& reduces peri-operative morbidity and mortality.

\section{INTRODUCTION:}

Nociceptive surgical stimulation is accompanied by increased hypothalamo-pituitary activity, which is generally referred to as the stress response to injury. This is manifested by a release of trophic hormones with consequent increase in cortisol, thyroxine and suppression of insulin ${ }^{1}$ Increased hypothalamic activity induced by nociceptive stimulation is accompanied by an increased traffic in sympathetic efferent tracts resulting in adrenergic response $\mathrm{e}^{2-4}$. Thus it has been proposed that an abrupt increase in circulating catecholemines may be associated with potentially severe hypertension, tachycardia, which in turn may cause cardiac arrhythmias, myocardial ischemia, left ventricular dysfunction and rupture of cerebral aneurysm ${ }^{5,6}$ in susceptible individuals ${ }^{7,8}$.

Until 1970's the stress response was thought to be an adaptive homeostatic response to a physiological insult, enhancing resistance to stress ${ }^{9}$. However, there is growing evidence that stress response is actually detrimental and is associated with postoperative morbidity. It has adverse effects on several key physiological systems like cardiovascular, respiratory and gastro-intestinal. In Cardio vascular system- stress response activates sympathetic nervous system, which increases myocardial oxygen demand by increasing heart rate and arterial pressure. Activation of sympathetic nervous system may also cause coronary artery vasoconstriction,

1. Faculty of Anaesthesiology, Institute of Child and Mothers Health, Matuail, Dhaka-1213

2. Sadar Hospital, Gazipur

3. Dept of Anaesthesia, Analgesia and Intensive Care Medicine, Bangabandhu Sheik Mujib Medical University, Dhaka

4. Appollo Hospitals, Dhaka 
reducing the supply of oxygen to the myocardium, which in turn would predispose to myocardial ischemia, aggravated by hypercoagulable state postoperatively-a stress response by $\mathrm{ADH}^{9}$.

Whilst there is general assumption that suppression of the autonomic response is advantageous. Edward et al in nineties demonstrated that in standardized clinical conditions, there was an increase in adrenaline production in patients receiving a balanced general anaesthesia as opposed to those receiving an epidural technique or a combination of both $^{10}$. However, Wylie and Churchill-Davidson (1998) have suggested that "stress free" anaesthesia is necessarily advantageous ${ }^{11}$.

Pre-medication is used to provide sedation and anxiolysis and to enhance the quality of induction, maintenance and recovery from anaesthesia. The ideal pre-medicant should be effective orally, with analgesic and non-emetic properties. A recent study has suggested that different pre-medication may lead to an alteration in sympatho-adrenal stress responses during surgery ${ }^{3}$. Several agents and regimens have been devised to control this stress induced haemodynamic responses including áblocker droperidol ${ }^{12}$ lignocaine ${ }^{13}$ low dose opioid ${ }^{14}$ and cervical extradural blockade ${ }^{10,15}$. But none of these have gained widespread acceptability.

There is one technique which is described as totally effective in abolishing haemodynamic responses i.e. large dose of either - Fentanyl $>50 \mu \mathrm{g} / \mathrm{kg}$ or morphine $>2 \mathrm{mg} / \mathrm{kg}$ have been shown to produce "stress free" condition in cardiac surgery ${ }^{4,16}$, yet this is although inappropriate for routine surgical practice. Halter et al in mid seventies ${ }^{17}$ demonstrated a consistent increase in plasma catecholemines concentration after surgical incision in-patient anaesthetized with nitrous oxide and halothane in oxygen with neuromuscular blocker vecuronium. Sigurdson et al much earlier ${ }^{18}$ suggested that the pre-medication may alter the magnitude of the sympathoadrenal response to noncardiac surgery.

It has been demonstrated that â-adrenoceptor blocker, in therapeutic doses, causes only modest reduction in cardiac output while decreasing the incidence of arrhythmia and myocardial ischaemia after laryngoscopy and intubation. It was recommended that its administration to be continued until the day of surgery ${ }^{14,15}$. Even a single dose of a â-blocker given as premedication decreases the incidence of episodes of myocardial ischaemia ${ }^{5}$. Ramanathan et al previously ${ }^{19}$ used Labetolol, a non selective á and â-blocker, at a dose of $0.15 \mathrm{mg} /$ $\mathrm{kg}$ I.V followed by 0.25 to $0.3 \mathrm{mg} / \mathrm{kg}$ I.V. every 3 minute to block the haemodynamic responses to tracheal intubation. Another group Mangano et al ${ }^{20}$ used Atenolol, a selective â-blocker, at a dose of $50 \mathrm{mg}$ bid per oral significantly reduces cardiovascular morbidity in abdominal surgery.

Propranolol was the first effective beta-blocker with prolonged clinical use and experience with it extends more widely than any other member of this group. By opposing the haemodynamic response to stress, it has an 'oxygen sparing' effect and this is of benefit to patients suffering from angina of effort, its action is comparable to that of atenolol at cardiac receptor site, with an addition of extra-cardiac site.

Propranolol has been shown to exert an alleviating effect in anxiety. There are several pieces of evidence to suggest that $\beta$-blocker work through a peripheral mechanism rather than within the CNS, although propranolol is relatively lipophilic and does gain entry to the CNS and it is most effective in performance anxiety \& thus stress, while other betablockers does not ${ }^{21}$. There is limited information on haemodynamic changes to propranolol produced by stress in abdominal surgery.

The cost of propranolol is generally low and it is used orally. Use of propanolol routinely in the preoperative preparation may replace the expensive preoperative cardiovascular testing. This may in turn substantially reduce the cost for cardiovascular testing.

As mentioned previously that information on haemodynamic changes to propranolol produced by stress during surgery is limited. Because of the easy availability and relative safety of propanolol, the study was undertaken to establish its effects on haemodynamic changes during surgery.

\section{MATERIALS AND METHODS:}

One hundred patients of ASA physical status admitted in hospitals for abdominal diseases had undergone operation of an average duration of 45 to 90 minutes under general anesthesia were selected for the study. Both male and female patients within age group 20-40 years were included. The protocol was approved by the Departmental Ethical 
Clearance Committee of BSMMU, Shahabag, Dhaka. Informed written consent was taken from each patient.

Each patient was allowed to draw one card randomly and grouped as Group I - control (who received placebo tablet sucrol) \& Group II - case (who received tablet propranolol $10 \mathrm{mg}$ ) as oral pre- medications at night before operation and one hour before operation of surgery. The patient and the investigator were blinded regarding the groups.

The anaesthetic procedures were explained and reassured to each patient After arrival of patient in operation theatre intravenous access was secured. Monitoring of heart rate and blood pressure were started. Pre-oxygenation was done for 3 minutes. Oxygen saturation was monitored from the beginning.

All the patients were induced with thiopentone sodium $(4-5 \mathrm{mg} / \mathrm{kg})$ and fentanyl $1 \mu \mathrm{gm} / \mathrm{kg}$. During the procedure ventilation of lung was assisted or controlled with $100 \%$ oxygen. No inhalation gases like $\mathrm{N}_{2} \mathrm{O}$ or halothane were used before intubation. Intubation was facilitated with Inj. Suxamethonium $1-1.5 \mathrm{mg} / \mathrm{kg}$ bolus. In those patients intubation took more than $40 \mathrm{sec}$ were excluded from the study. Anaesthesia was maintained with $70 \% \mathrm{~N}_{2} \mathrm{O}$ in $\mathrm{O}_{2}$ and $0.5 \mathrm{v} / \mathrm{v}$ percent halothane. Muscle relaxant used was vecuronium with initial bolous dose of 0.08-0.1 $\mathrm{mg} / \mathrm{kg}$ \& increment with one third of bolous doses. Analgesia was maintained with incremental doses of fentanyl. At the end of the operation extubation was done with Inj Neostigmine $(0.05 \mathrm{mg} / \mathrm{kg})$ and Inj Atropine $(0.02 \mathrm{mg} / \mathrm{kg})$.

\section{Table-I}

Age, weight and height of the study subjects
Heart rate and automated non-invasive arterial blood pressure were recorded before intubation, just after intubation, at 10 minutes interval during the operative procedure and after extubation, using a Datex Ohmeda (Helsinki, Finland) monitor. Rate pressure product (RPP) values were taken as derived values from multiplication of heart and systolic arterial blood pressure.

Data collected in a pre-designed data collection sheet were complied on a master chart. All data are plotted on sigma plot and all results are expressed as mean \pm SD. Data were analyzed by students unpaired ' $\mathrm{t}$ ' test and considered significant if $\mathrm{p}<0.05$.

\section{OBSERVATION AND RESULTS:}

All the observations were presented in a tabulated form. Observed parameters were expressed as mean \pm SD.

The groups were homogenous as regard to age, weight, height and ASA physical status. The duration of surgery was also statistically matched with each other. The effect of placebo and propranolol on heart rate, systolic arterial pressure and rate pressure product at immediately after intubations and during pre-operative period showed significant difference than that of base line values (Table-I).

Baseline values of heart rate of the two groups were similar. Base line systolic arterial pressures (SAP) were also similar. But it was significantly different within groups. Heart rate was significantly higher in placebo group (group I) immediately after intubation and at 10, 20,30, 40 minutes of peroperative period compared to the propranolol group (group II) (Table II).

\begin{tabular}{lcccc}
\hline Variables & Group I & Group II & t value & p value \\
\hline Age (yrs) & $31.2 \pm 9.4$ & $33.3 \pm 9.1$ & -1.104 & 0.272 \\
Weight $(\mathrm{kg})$ & $50.2 \pm 5.9$ & $49.6 \pm 6.2$ & 0.462 & 0.645 \\
Height $(\mathrm{cm})$ & $154.4 \pm 3.4$ & $155.2 \pm 4.7$ & -0.729 & 0.468 \\
\hline
\end{tabular}

Table-II

Changes in preoperative Heart Rate (bpm) during upper abdominal surgery

\begin{tabular}{lccccccccc}
\hline Groups & Baseline & \multicolumn{7}{c}{ Heart rate at time after intubations } & Post \\
\cline { 3 - 8 } & & $0 \mathrm{~min}$ & $10 \mathrm{~min}$ & $20 \mathrm{~min}$ & $30 \mathrm{~min}$ & $40 \mathrm{~min}$ & $50 \mathrm{~min}$ & $60 \mathrm{~min}$ & operative \\
\hline Group I & $76 \pm 6$ & $109 \pm 8$ & $102 \pm 9$ & $95 \pm 9$ & $88 \pm 7$ & $83 \pm 6$ & $82 \pm 6$ & $80 \pm 11$ & $111 \pm 7$ \\
Group II & $74 \pm 4$ & $77 \pm 6$ & $73 \pm 7$ & $69 \pm 6$ & $67 \pm 6$ & $66 \pm 4$ & $66 \pm 5$ & $66 \pm 6$ & $75 \pm 6$ \\
t value & 2.256 & 22.048 & 17.777 & 16.658 & 16.995 & 14.549 & 8.648 & 3.430 & 31.57 \\
p value & 0.026 & $<0.0001$ & $<0.0001$ & $<0.0001$ & $<0.0001$ & $<0.0001$ & $<0.0001$ & 0.003 & $<0.0001$ \\
\hline
\end{tabular}

Values are expressed as mean $\pm \mathrm{SD}$. P value expressed as significant if $\mathrm{p}<0.05$ (CI-95\%). 
Table-III

Changes in preoperative systolic arterial pressure $(\mathrm{mmHg})$ during upper abdominal surgery

\begin{tabular}{lccccccccc}
\hline Groups & Baseline & \multicolumn{6}{c}{ Systolic blood pressure at different time after intubations } & Post- \\
\cline { 3 - 8 } & & $0 \mathrm{~min}$ & $10 \mathrm{~min}$ & $20 \mathrm{~min}$ & $30 \mathrm{~min}$ & $40 \mathrm{~min}$ & $50 \mathrm{~min}$ & $60 \mathrm{~min}$ & operative \\
\hline Group I & $115 \pm 7$ & $128 \pm 6$ & $123 \pm 6$ & $119 \pm 7$ & $117 \pm 7$ & $117 \pm 6$ & $117 \pm 6$ & $119 \pm 5$ & $125 \pm 5$ \\
Group II & $114 \pm 7$ & $116 \pm 7$ & $111 \pm 10$ & $112 \pm 9$ & $112 \pm 8$ & $113 \pm 5$ & $111 \pm 5$ & $110 \pm 2$ & $116 \pm 8$ \\
t value & 0.838 & 9.377 & 7.492 & 4.477 & 3.543 & 3.351 & 3.346 & 2.934 & 6.130 \\
p value & 0.404 & $<0.0001$ & $<0.0001$ & 0.00002 & 0.0006 & 0.0012 & 0.0016 & 0.0092 & $<0.0001$ \\
\hline
\end{tabular}

Values are expressed as mean $\pm \mathrm{SD}$. P value expressed as significant if $\mathrm{p}<0.05$ (CI-95\%).

Baseline values of systolic arterial pressure (SAP) of the two groups were similar. But it was significantly different between groups. Systolic arterial pressure (SAP) values were found to be significantly higher in placebo group immediately after intubations and at 10,20,30, 40 minutes of per-operative period comparer to the propranolol group (Table III).

\section{DISCUSSION:}

Surgical anaesthesia is a harmless and reversible insensibility, which allows operation of considerable magnitude to be carried out hindrance to the surgeon or to detriment to the patient. Anaesthetic stages consist of sleep, analgesia and muscle relaxation, which could now be produced by separate and several medications. But yet nociceptive surgical stimulation is accompanied by increased hypothalamo- pituitary activity, which is manifested by a release of trophic hormones with consequent increase in cortisol, thyroxine \& suppression of insulin ${ }^{1}$. Increased hypothalamic activity is accompanied by an increased traffic in sympathetic efferent tracts resulting in adrenergic responses in $1970^{2,3}$. In cardio-vascular system stress response activates sympathetic nervous system, which increases myocardial oxygen demand by increasing heart rate and arterial blood pressure ${ }^{9}$.

The goal of adequate anaesthesia is to keep the patient throughout the operative procedure "stress free". Edwards et al earlier demonstrated that in standardized clinical conditions, there was an increase in adrenaline production in patients receiving a general anaesthesia as opposed to those receiving an epidural technique or a combination of both ${ }^{10}$. A recent study has suggested that different pre-medication may lead to an alteration in sympathoadrenal stress response during surgery ${ }^{3}$.
Several agents and regimens have been devised to control this stress induced haemodynamic response including alpha-blocker, droperidol ${ }^{12}$, lignocaine ${ }^{13}$, low dose opioid ${ }^{14}$, and cervical extradural blockade ${ }^{15}$.

So search for an appropriate and easily available pre-medicant to make general surgical anesthesia more stress-free is going on for the last few years. It has been demonstrated that beta-adrenoceptor blocker, in low therapeutic doses, causes only modest reduction in cardiac output while decreasing the incidence of arrhythmia and myocardial ischaemia after laryngoscope and intubations ${ }^{14,15}$. Even a single dose of beta-blocker given as premedications decreases the incidence of myocardial ischaemia ${ }^{5}$. Propranolol has been shown to exert a alleviating effect in anxiety in addition to beta-blockade. Furthermore it is generally of low cost and there is convenience about its dosing and routes of administration.

The result of this trial demonstrate that in patients who are not at risk for coronary artery disease and who are undergoing non cardiac surgery, stress induced haemodynamic response can be substantially reduced by premeditation with low dose oral propranolol. In pre-operative period heart rate of group I is (76.32 \pm 5.82$)$ and remains slightly higher than the group II (74.02 \pm 4.24$)$ but after surgical incision, heart rate rises sharply $(109.10 \pm 8.25)$ in group-I where in group-II heart rate (76.6 \pm 6.37$)$ remains close to pre-operative value. Throughout the operative period result shows a significant value irrespective of heart rate, systolic arterial pressure and simultaneously rate pressure product. Pine et al found that a concentration of propranolol of $100 \mathrm{ng} / \mathrm{ml}$ produce complete receptor blockade, where as $8 \mathrm{ng} / \mathrm{ml}$ produce a $50 \%$ blockade ${ }^{22}$. In our study, we are not able to measure 
serum concentration of propranolol but it can be shown from the performed study that $10 \mathrm{mg}$ bid oral dose can maintain much more than $8 \mathrm{ng} / \mathrm{ml}$ plasma level which is sufficient to produce therapeutic blockade. At the same time Johnson et al showed that maximum improvement in angina pectoris occurs at $64 \%$ to $98 \%$ beta blockade ${ }^{23}$.

There is the rationale for using low dose propranolol pre-medication for the prevention of peri-operative risk of myocardial ischaemia. Studies conducted over the past decade have established the association between chances of preoperative myocardial ischaemia is more in untreated patients than those who gets some of any sympatholytic agents. The study, we performed here, have demonstrated an association between peri-operative ischaemia and an elevated heart rate and have suggested that mitigation of this heart rate response may reduce the incidence or severity of ischaemia. Thus, we concluded that oral pre medication with low dose propranolol, as could attenuate the heart rate response and limit the development of ischaemia, might substantially reduce longer-term cardiac complications.

\section{CONCLUSION:}

From this study it may be concluded that oral premedication with low dose propranolol significantly attenuates stress induced haemodynamic changes in upper abdominal surgery.

\section{REFERENCES:}

1. Kaufman L. Anaesthesia and endocrine response; in anaesthesia received-II. London: Churchill Livingstone 1984.

2. Forbes AM and Dally FG. Acute hypertension during induction of anaesthesia and endotracheal intubation in the Normotensive man. Br J Anaesth, 1970; 42: 618-628.

3. Derbyshire DR, Chmielewski A, Fell D, Vater M, Achola K, Smith G. Catecholemines response to tracheal intubation. Br J Anaesth, 1983; 55: 855.

4. Stanly TH, Berman L, Green O et al. Plasma Catecholemines and cortisol responses to fentanyl-oxygen anaesthesia for coronary artery operation. Anaesthesiology, 1980; 53: 250.

5. Foex P. á and beta adrenoceptor antagonist. Br J Anaesth 1984; 56: 751-65.
6. Prys-Roberts G, Greene LT, Meloche R, Foex P. Study of anaesthesia in relation to hypertension Haemodynamic consequences of induction of endotracheal intubation $\mathrm{Br} J$ Anaesth, 1971; 43: 531-547.

7. Cummings MF, Russell WJ, Frewin DB (1983). Effects of pancuronium and alcuronium on the changes in arterial pressure and plasma catecholemines concentrations during tracheal intubation. Br J Anaesth, 1983; 55: 619.

8. Russell WJ, Morris RG, Frewin DB et al. Changes in plasma catecholamine concentrations during indotracheal intubation. Br J Anaesth; 1981; 53: 837- 839.

9. Aitkenhead R, Rowbotham DJ and Smith G. Text Book of Anaesthesia. 4th Edition. London: Churchill Livingstone, 2001; p301-303.

10. Edwards et al. Anaesthesia trauma strees and leukocyte migration; influence of general anaesthesia and surgery. Euro J Anaesth 1990; 7: 185-96.

11. Wylie and Churchill-Davidson. A practice of anaesthesia. 6th Edition. London: Edward Arnold; 1995, p589.

12. Curran J, Crowley M, O Sullivan G. Droperidol and endotracheal intubation Attenuation of pressor response to laryngoscopy and tracheal intubation. Anaesthesia, 1980; 35: 290.

13. Stoelting RK. Blood pressure and heart rate changes during short duration laryngoscopy for tracheal intubation: influence of viscous or intravenous lidocaine Anaesth Analg, 1978; 57: 197.

14. Kautto UM. Attenuation of the circulatory responses at laryngoscopy and intubation by fentanyl. Acta Anaesthesia Scand, 1982; 26: 217

15. Dohi S, Nishikawa T, Ujike Y, Mayumi T. Circulatory responses to airway stimulation and cervical epidural blockade. Anaesthesiology, 1982; 57: 359.

16. Hoar PF, Nelson NT, Mangano DI, Bainton CR, Hickey RF. Adrenergic responses to morphine diazepam anaesthesia for myocardial revascularization. Anaesth Analg 1981; 60: 406. 
17. Halter JB, Pflug AE, Porte D. Mechanism of plasma catecholamine increases during surgical stress in man. $J$ Clin Endocrinal Metab, 1977; 45: 936.

18. Sigurdsson GH, Lindahl S, Norden N. Influence on the sympatho-endocrine responses and cardiac arrhythmia in halothane anaesthesia. Br J Anaesth 1983; 55: 961.

19. Ramanathan J, Sibai B, Mabie WC, Chauhan $\mathrm{D}$, Ruiz AG. The use of lebetalol for attenuation of the hypertensive response to endotracheal intubation in preeclampsia $\mathrm{Am} \mathrm{J} \mathrm{Obs}$ Gyneacol, 1988; 159: 650-654.

20. Mangano DT, Layug EL, Wallace A, Tateo I. Effect of atenolol on mortality and cardiovascular morbidity after noncardiac surgery. Multicenter Study of Perioperative Ischemia Research Group. N Engl J Med, 1996; 335: 1713-1720.

21. Vickers MD, Morgan M, Spencer PSJ. Drugs in Anaesthetic and Intensive Care Practice. 8th edition. London: Butterworth-Heinemannn Ltd; p402.

22. Pine M, Favrot L, Smith S et al. Correlation of plasma propranolol concentration with therapeutic response in patients with angina pectoris. Circulation, 1975; 52: 886-896.

23 Jonsson G, Regardh CG. Clinical Pharmacokinetice of $ß$-adrenoreceptor blocking drugs. Clinical Pharmacokinet, 1976; 1: 233263. 